\title{
Daptomycin and methicillin-resistant Staphylococcus aureus isolated from a catheter-related bloodstream infection: a case report
}

\author{
Fernanda S Cavalcante ${ }^{1}$, Dennis de C Ferreira ${ }^{1,2}$, Raiane C Chamon ${ }^{1}$, Thaina M da Costa ${ }^{1}$, Fernanda Maia ${ }^{3}$,
} Elaine M Barros ${ }^{4}$, Tatiana Silva Dantas ${ }^{3}$ and Kátia R N dos Santos ${ }^{1^{*}}$

\begin{abstract}
Background: Daptomycin is an alternative option for the treatment of catheter-related bloodstream-infections caused by methicillin-resistant Staphylococcus aureus. This study reports a case of a daptomycin and methicillin-resistant Staphylococcus aureus isolate recovered from the blood of a Brazilian patient undergoing hemodialysis.

Case presentation: A 64-year-old white male patient suffering from diabetes mellitus, systolic hypertension, heart disease with a coronary stent, obesity and chronic renal failure and on use of permcath catheter developed a catheter-related bloodstream-infection by a daptomycin-methicillin-resistant Staphylococcus aureus isolate after one month of daptomycin therapy. The isolate was identified as the SCCmec II/USA100/sequence type 5 lineage by molecular techniques.

Conclusions: In this work we described a Brazilian patient with bloodstream infection caused by a daptomycin and methicillin-resistant Staphylococcus aureus belonging to the lineage USA100/sequence type 5. Our case highlights the careful management of bloodstream infections and the importance of the judicious use of antimicrobials due the possibility of daptomycin-resistance developing among S. aureus isolates, especially in patients under hemodialysis, which are frequently exposed to vancomycin and daptomycin therapy.
\end{abstract}

Keywords: MRSA, Daptomycin, Catheter-related bloodstream-infection, SCCmec II

\section{Background}

Methicillin-resistant Staphylococcus aureus (MRSA) is one of the most important causes of catheter-related bloodstream-infections (CRBSI) among hemodialysis patients $[1,2]$ and daptomycin is an alternative option for the treatment [3]. In Brazil, there is only one report describing two isolates of daptomycin-resistant $S$. aureus; however no information was given concerning the clinical conditions of the patients [4]. This study reports the case of a daptomycin-resistant MRSA isolate recovered from the blood of a Brazilian patient undergoing

\footnotetext{
* Correspondence: santoskrn@micro.ufrj.br

'Departamento de Microbiologia Médica, Laboratório de Infecção Hospitalar/ UFRJ, Instituto de Microbiologia Paulo de Góes, Universidade Federal do Rio de Janeiro, Av. Carlos Chagas Filho, 373, CEP: 21941-590, Rio de Janeiro, Brazil Full list of author information is available at the end of the article
}

hemodialysis, also the susceptibility profile and molecular characteristics of the isolate are described.

\section{Case presentation}

A 64-year-old white male, resident in Rio de Janeiro, has been managing our hospital due to insulin dependent diabetes mellitus, arterial hypertension, chronic coronary disease and renal failure. In August of 2011, he began hemodialysis in our hospital as his renal glomerular function became worse. In March 2012, one month after implanting a permcath catheter he came for the emergency department with signs of infection to elucidate. The results of the microscopic examination of urinary sediment showed 15 to 20 white blood cells (WBC), and so cephalexin was begun to treat a possible urinary infection. However, three days after the antibiotic therapy was begun 
the urinary sample did not show any bacterial growth. The patient returned with signs of systemic inflammatory response syndrome. A clinical examination of the patient showed an inflammation at the insertion site of the hemodialysis catheter. The patient was admitted in our critical care unit on 7 March 2012 with suspicion of CRBSI. The catheter was removed and another was implanted in his right femoral vein. Two samples of peripheral blood were sent for culture and empiric therapy with vancomycin and piperacillin-tazobactam was initiated within one hour of admittance to the ICU. The microbiology analysis of blood samples revealed MRSA. The therapy was changed to daptomycin on 12 March 2012. After 30 doses of daptomycin intravenously based on his glomerular filtrate rate (GFR), the patient was discharged from the hospital on 18 April.

On 9 May 2012, 20 days after the last dose of daptomycin, he returned to the hemodialysis department with a respiratory syndrome. The chest computed tomography demonstrated signs of pneumonia. Therefore, three samples of peripheral blood were sent to the hospital laboratory. Antibiotic therapy (vancomycin, meropenem and trimethoprim-sulfamethoxazole) was initiated according to the microbiology data. The vascular catheter was withdrawn because there was free purulent secretion at the insertion site. Once again, a new catheter was implanted, this time, in the right femoral vein for hemodialysis therapy.

The new MRSA isolate from the blood samples showed a multidrug resistance pattern. The isolate was resistant to ciprofloxacin, rifampin, chloramphenicol, clindamycin and erythromycin but showed susceptibility to linezolid, quinupristin-dalfopristin, tetracycline and trimethoprim-sulfamethoxazole by the disk-diffusion test. The minimum inhibitory concentration (MIC) assessed by broth microdilution method showed MICs of $>256 \mu \mathrm{g} / \mathrm{mL}, 4 \mu \mathrm{g} / \mathrm{mL}$ and $8 \mu \mathrm{g} / \mathrm{mL}$ for oxacillin, vancomycin and daptomycin, respectively. The SCCmec typing [5], pulsed field gel electrophoresis [6] and multilocus sequence typing (MLST) [7] revealed that the isolate belonged to the SCCmec II/USA100/ST5 lineage. After 3 months in hospital, the patient died from a hemorrhagic stroke and pneumonia associated mechanical ventilation due to Acinetobacter baumanni.

\section{Discussion}

Methicillin-resistant S. aureus (MRSA) infections are becoming more frequent and are less easily treated with the current antibiotic agents. There is a high incidence of catheter-related bloodstream-infections (CRBSI) caused by MRSA among patients undergoing hemodialysis and the mortality rates are also high $[1,2]$. Although vancomycin is the mainstay treatment for MRSA complicated infections, the experts observed failure of vancomycin therapy associated to high mortality rates have been observed when
MRSA isolates exhibits MIC $\geq 2 \mu \mathrm{g} / \mathrm{mL}$ [8]. According to Clinical Practice Guidelines for the Diagnosis and Management of CRBSI daptomycin is recommended when MRSA isolates exhibit vancomycin $\mathrm{MIC}>2 \mu \mathrm{g} / \mathrm{mL}$. In this study, the MRSA isolate recovered from the blood of the patient had a $\mathrm{MIC}=4 \mu \mathrm{g} / \mathrm{ml}$ to vancomycin, justifying the antibiotic therapy of daptomycin.

Clinical cases have shown decreasing susceptibility of S. aureus to daptomycin due to antibiotic pressure exerted by vancomycin, and vice versa $[9,10]$. Data from 30 MRSA isolates recovered from bloodstream infections between 2011 and 2013 were evaluated by our group. The results showed that among 13 isolates with a vancomycin $\mathrm{MIC}=1 \mu \mathrm{g} / \mathrm{ml}, 85 \%$ showed daptomycin MIC $\geq 1 \mu \mathrm{g} / \mathrm{ml}$. Likewise, among 16 isolates with vancomycin MIC $\geq 2 \mu \mathrm{g} / \mathrm{ml} 43.7 \%$ also presented MIC $\geq 2 \mu \mathrm{g} / \mathrm{ml}$ for daptomycin (Table 1; data not published). Kirby et al. [11] reported an infection by daptomycin-resistance $S$. aureus from a catheter-related BSI in a hemodialysis patient. The authors confirmed that the MIC to daptomycin of this isolate increased from 0.25 to 0.5 after nine months of various schemes of vancomycin therapy, even though the patient had never received daptomycin. After five months of daptomycin therapy be started, the MIC value to this drug increased to $62 \mu \mathrm{g} / \mathrm{mL}$. In our case, after 30 doses of daptomycin, the resistance to this drug was detected in the MRSA with MIC $4 \mu \mathrm{g} / \mathrm{mL}$ for vancomycin.

Nevertheless, resistance to daptomycin in S. aureus isolates remains rare. A study conducted by a surveillance program analyzed $49,000 \mathrm{~S}$. aureus isolates collected from around the world, between 2005 and 2008, and found only $53(0.05 \%)$ daptomycin-resistant isolates. Only one was recovered in Latin American. However, Dabul \& Camargo [4] recently reported two daptomycin-resistant $S$. aureus isolates in Brazil, collected from a catheter tip and a leg abscess in different patients. Both the isolates were methicillin-resistant and belonged to the SCCmec II/ USA100/ST5 lineage, the same profile found in this study. This lineage has established itself in Brazilian hospitals $[12,13]$. The genetic similarity found between the isolates indicates a facility of this genotype to develop resistance to daptomycin.

\begin{tabular}{|c|c|c|c|c|}
\hline \multirow{2}{*}{$\begin{array}{l}\text { MIC of vancomycin } \\
\text { ( } \mathrm{N}^{\circ} \text { of isolates) }\end{array}$} & \multicolumn{4}{|c|}{ MIC of daptomycin $\mathrm{N}^{\circ}(\%)$ of isolates } \\
\hline & 0.5 & 1 & 2 & 4 \\
\hline $0.5(1)$ & $1(100)$ & 0 & 0 & 0 \\
\hline $1(13)$ & $2(15.4)$ & $7(53.8)$ & $3(23.1)$ & $1(7.7)$ \\
\hline $2(12)$ & 0 & $7(58.3)$ & $4(3.3)$ & $1(8.4)$ \\
\hline $4(4)$ & $1(25)$ & $1(25)$ & $1(25)$ & $1(25)$ \\
\hline
\end{tabular}




\section{Conclusion}

Vancomycin and daptomycin resistance in $S$. aureus are especially worrying in hemodialysis patients due to the high incidence of CRBSI [1,2] which are frequently treated with these antimicrobials. In this study we described the CRBSI of a Brazilian patient caused by a daptomycinresistant MRSA belonging to a lineage already involved in daptomycin-resistance in Brazil. Thus, our case highlights the careful management of BSI infections and the importance of the judicious use of antimicrobials due the possibility of daptomycin-resistance developing among $S$. aureus isolates.

\section{Consent}

Written informed consent was obtained from the patient's spouse for publication of this Case Report and any accompanying images. A copy of the written consent is available for review by the Editor-in-Chief of BMC Research Notes.

\section{Abbreviations \\ SCCmec: Staphylococcal chromosome cassette mec; ST: Sequence type; MRSA: Methicillin-resistant S. aureus; CRBSI: Catheter-related bloodstream- infections; WBC: White blood cells; GFR: Glomerular filtration renal; MIC: Minimum inhibitory concentration; MLST: Multilocus sequence typing.}

\section{Competing interests}

The authors declare that they have no competing interests.

\section{Authors' contribution}

FSC, DCF, NLPI, TMC and RCC have made substantial contributions to conception, design, analysis and interpretation of data; FM, EMB and TSD carried out the collection of the isolates and acquisition of data; FSC, RCC, KRNS have been involved in drafting the manuscript and revising it critically for important intellectual content; and FSC, DCF and KRNS have given final approval of the version to be published. All authors read and approved the final manuscript.

\section{Acknowledgments}

This study was supported by Brazilian grants from Fundação Carlos Chagas Filho de Amparo à Pesquisa do Estado do Rio de Janeiro (FAPERJ), Conselho Nacional de Desenvolvimento Científico e Tecnológico (CNPq), Coordenação de Aperfeiçoamento Pessoal de Nível Superior (CAPES), Fundação Universitária José Bonifácio (FUJB) and Programa de Núcleos de Excelência (PRONEX).

\section{Author details}

'Departamento de Microbiologia Médica, Laboratório de Infecção Hospitalar/ UFRJ, Instituto de Microbiologia Paulo de Góes, Universidade Federal do Rio de Janeiro, Av. Carlos Chagas Filho, 373, CEP: 21941-590, Rio de Janeiro, Brazil.

${ }^{2}$ Escola de Odontologia, Universidade Veiga de Almeida, Rio de Janeiro, Brazil. ${ }^{3}$ Hospital Naval Marcilio Dias, Rio de Janeiro, Brazil. ${ }^{4}$ Faculdade de Ciências Farmacêuticas, Universidade de São Paulo, São Paulo, Brazil.

Received: 11 August 2014 Accepted: 9 October 2014

Published: 25 October 2014

\section{References}

1. Nguyen DB, Lessa FC, Belflower R, Mu Y, Wise M, Nadle J, Bamberg WM, Petit S, Ray SM, Harrison LH, Lynfield R, Dumyati G, Thompson J, Schaffner W, Patel PR, Active Bacterial Core Surveillance (ABCS) MRSA Investigators of the Emerging Infections Program: Invasive methicillin-resistant Staphylococcus aureus infections among patients on chronic dialysis in the United States, 2005-2011. Clin Infect Dis 2013, 57:1393-1400.
2. Gnass M, Gielish C, Acosta-Gnass S: Incidence of nosocomial hemodialysisassociated bloodstream infections at a county teaching hospital. Am J Infect Control 2014, 42:182-184.

3. Mermel LA, Allon M, Bouza E, Craven DE, Flynn P, O'Grady NP, Raad II, Rijnders BJ, Sherertz RJ, Warren DK: Clinical practice guidelines for the diagnosis and management of intravascular catheter-related infection, 2009 Update by the Infectious Diseases Society of America. Clin Infect Dis 2009, 49:1-45.

4. Dabul AN, Camargo IL: Molecular characterization of methicillin-resistant Staphylococcus aureus resistant to tigecycline and daptomycin isolated in a hospital in Brazil. Epidemiol Infect 2014, 142:479-483.

5. Milheiriço C, Oliveira DC, De Lencastre H: Update to the multiplex PCR strategy for assignment of mec element types in Staphylococcus aureus. Antimicrob Agents Chemother 2007, 51:3374-3377.

6. Vivoni AM, Diep BA, De Gouveia Magalhães AC, Santos KR, Riley LW, Sensabaugh GF, Moreira BM: Clonal composition of Staphylococcus aureus isolates at a Brazilian university hospital: identification of international circulating lineages. J Clin Microbiol 2006, 44:1686-1691.

7. Enright MC, Day NP, Davies CE, Peacock SJ, Spratt BG: Multilocus sequence typing for characterization of methicillin-resistant and methicillin-susceptible clones of Staphylococcus aureus. J Clin Microbiol 2000, 38:1008-1015.

8. Wang JI, Wang JT, Sheng WH, Chen YC, Shang SC: Nosocomial methicillinresistant Staphylococcus aureus (MRSA) bacteremia in Taiwan: Mortality analyses and the impact of vancomycin, $\mathrm{MIC}=2 \mathrm{mg} / \mathrm{L}$, by the broth microdilution method. BMC Infect Dis 2010, 10:159.

9. Sakoulas G, Gold HS, Cohen RA, Venkataraman L, Moellering RC, Eliopoulos GM: Effects of prolonged vancomycin administration on methicillin-resistant Staphylococcus aureus (MRSA) in a patient with recurrent bacteraemia. J Antimicrob Chemother 2006, 57:699-704.

10. Patel JB, Jevitt LA, Hageman J, McDonald LC, Tenover FC: An association between reduced susceptibility to daptomycin and reduced susceptibility to vancomycin in Staphylococcus aureus. Clin Infect Dis 2006, 42:1652-1653.

11. Kirby A, Mohandas K, Broughton C, Neal TJ, Smith GW, Pai P, Nistal De Paz C: In vivo development of heterogeneous glycopeptide-intermediate Staphylococcus aureus (hGISA), GISA and daptomycin resistance in a patient with meticillin-resistant Staphylococcus aureus endocarditis. J Med Microbiol 2009, 58(Pt 3):376-380.

12. Caboclo RM, Cavalcante FS, lorio NL, Schuenck RP, Olendzki AN, Felix MJ, Chamon RC, Dos Santos KR: Methicillin-resistant Staphylococcus aureus in Rio de Janeiro hospitals: dissemination of the USA400/ST1 and USA800/ ST5 SCCmec type IV and USA100/ST5 SCCmec type II lineages in a public institution and polyclonal presence in a private one. Am J Infect Control 2013, 41:e21-e26.

13. Cavalcante FS, Schuenck RP, Caboclo RM, Ferreira Dde C, Nouér SA, Santos KR: Tetracycline and trimethoprim/sulfamethoxazole at clinical laboratory: can they help to characterize Staphylococcus aureus carrying different SCCmec types? Rev Soc Bras Med Trop 2013, 46:100-102.

doi:10.1186/1756-0500-7-759

Cite this article as: Cavalcante et al:: Daptomycin and methicillinresistant Staphylococcus aureus isolated from a catheter-related bloodstream infection: a case report. BMC Research Notes 2014 7:759.

\section{Submit your next manuscript to BioMed Central and take full advantage of:}

- Convenient online submission

- Thorough peer review

- No space constraints or color figure charges

- Immediate publication on acceptance

- Inclusion in PubMed, CAS, Scopus and Google Scholar

- Research which is freely available for redistribution 